\title{
Erratum
}

\section{Prediction of the Rate of Decline in Cognitive Function in Alzheimer's Disease: A Correction}

\author{
Sigurd Johnsen ${ }^{a}$ Steve Hughes ${ }^{a}$ Roger Bullock ${ }^{b}$ lan Hindmarch ${ }^{a}$ \\ aHPRU Medical Research Centre, University of Surrey, Guildford, and bVictoria Hospital, Swindon, UK
}

The conclusions and practical recommendations put forward in our paper [1] were based on results from applying discriminant analysis to demographic data comprising the placebo groups from various studies of the progression of Alzheimer's disease. The approach advocated [1] appeared to provide a convenient and inexpensive way of accurately distinguishing, at diagnosis, those dementia patients whose mental state would deteriorate rapidly from those with a slower rate of decline. Unfortunately, due to a misunderstanding about the nature of the format of the original data set, the sensitivity and specificity of the technique in these particular circumstances are now reported as being substantially below the level implied by the previously presented results [1], which are now judged to be erroneous. In short, the original result file contained duplicated data, which were unwittingly treated as coming from separate distinct subjects with the result that the population of patients to which discriminant analysis was applied contained repeated sets of data for some patients.

In this correction are presented, side by side, the invalid results from the previous paper [1] and the results of correctly analysing an augmented data set comprising the original (but corrected) data set together with data of exactly the same type for 303 additional subjects. These placebo data represent a close approximation to an observational data set. The aim of this correction is to facilitate the reader's judgement of the extent to which the earlier conclusions [1] are now weakened.

The results (incorrect) from the previous paper [1] are shown in tables 1 and 2.

From tables 3 and 4, it can be seen that the models, using logistic regression, predict the numbers of subjects who remained stable over the 26-week period, with sensitivities of 58\% (model 1) and 60\% (model 2). Tables 3 and 4 also lead to (correct) specificities of $61 \%$ (model 1) and 64\% (model 2) for subjects who deteriorated. All per-
Table 1. (Erroneous) results of discriminant analysis based on baseline ADAS-cog score and demographic variables (model 1)

\begin{tabular}{lrcr}
\hline Actual classification & \multicolumn{3}{l}{ Classification by model } \\
\cline { 2 - 4 } & stable & deterioration & unclassified \\
\hline Stable & 873 & 11 & 13 \\
Deterioration & 9 & 370 & 3 \\
\hline
\end{tabular}

Table 2. (Erroneous) results of discriminant analysis based on baseline MMSE score and demographic variables (model 2)

\begin{tabular}{lccc}
\hline \multirow{2}{*}{ Actual classification } & \multicolumn{3}{c}{ Classification by model } \\
\cline { 2 - 4 } & stable & deterioration & unclassified \\
\hline Stable & 851 & 6 & 15 \\
Deterioration & 8 & 357 & 2 \\
\hline
\end{tabular}

centages are rounded to the nearest integers. It must now be concluded that the technique proposed earlier [1] does not, at least in its present form, constitute a useful addition to the armoury of methods presently available for predicting the rate of decline of cognitive function of Alzheimer's disease sufferers. However, further model-

\begin{tabular}{ll}
\hline KARGER & ( 2004 S. Karger AG, Basel \\
1420-8008/04/0184-0349\$21.00/0 \\
$\begin{array}{l}\text { Fax +41613061234 } \\
\begin{array}{l}\text { E-Mail karger@karger.ch } \\
\text { www.karger.com }\end{array}\end{array}$ & $\begin{array}{l}\text { Accessible online at: } \\
\text { www.karger.com/dem }\end{array}$
\end{tabular}

\author{
Dr. Sigurd Johnsen \\ HPRU Medical Research Centre, University of Surrey \\ Guildford, GU2 7XP (UK) \\ Tel. +44 1483683721, Fax +44 1483689790 \\ E-Mail s.johnsen@surrey.ac.uk
}


Table 3. (Correct) results of logistic regression based on baseline ADAS-cog score and demographic variables (model 1)

\begin{tabular}{llll}
\hline \multirow{2}{*}{ Actual classification } & \multicolumn{3}{l}{ Classification by model } \\
\cline { 2 - 4 } & stable & deterioration & unclassified \\
\hline Stable & 289 & 212 & 0 \\
Deterioration & 74 & 116 & 0 \\
\hline
\end{tabular}

Table 4. (Correct) results of logistic regression based on baseline MMSE score and demographic variables (model 2)

\begin{tabular}{lccl}
\hline \multirow{2}{*}{ Actual classification } & \multicolumn{3}{c}{ Classification by model } \\
\cline { 2 - 4 } & stable & deterioration & unclassified \\
\hline Stable & 300 & 200 & 0 \\
Deterioration & 69 & 121 & 0 \\
\hline
\end{tabular}

ling of the rate of cognitive decline of the patients, on whose data both the previous [1] and the present findings are based, has the potential to throw light on the underlying processes involved in the cognitive decline of dementia sufferers, and this could be the object of further study.

\section{Acknowledgements}

The authors are grateful to Novartis Pharmaceuticals for supplying the original data, for pointing out the errors made in the analysis of the data and for supplying the augmented data set. The authors are also grateful to the Editor of Dementia and Geriatric Cognitive Disorders for publishing this correction.

\section{Reference} Prediction of the rate of decline in cognitive function in Alzheimer's disease: A model based on simple demographic data and widely used rating scales. Dement Geriatr Cogn Disord 2003; $16: 276-282$. 